\title{
Point-of-care Procalcitonin Guidance to Reduce Antibiotic Use in Critically III Patients: A Randomized Controlled Trial.
}

\author{
Wan Fadzlina Wan Muhd Shukeri ${ }^{1}$, Azrina Md. Ralib ${ }^{1}$, Mohd Basri Mat-Nor ${ }^{1}$ \\ ${ }^{1}$ Department of Anesthesiology and Intensive Care, Kulliyyah of Medicine, \\ International Islamic University
}

Presenter: Wan Fadzlina Wan Muhd Shukeri

Introduction: Antibiotic therapy is of great importance in sepsis but prolonged duration can add to the emergence of antibiotic resistance. We aimed to examine whether point-of-care (POC) procalcitonin (PCT) guidance can safely reduce the duration of antibiotic use in infected critically ill patients. Materials and Methods: Eighty adult patients admitted to or acquired sepsis in the intensive care unit (ICU) were enrolled in this randomized controlled trial. Patients were allocated to either POC PCT-guided intervention arm $(n=40)$ or the control arm, in which antibiotic therapy followed local guidelines $(n=40)$. In the PCT-guided arm, antibiotic treatment was discontinued if clinical signs of infection improved and the PCT concentration decreased by $>80 \%$ of its peak value, or when it reaches a value of $<0.5 \mathrm{~g} / \mathrm{L}$. Results: The mean duration of antibiotic use for PCT arm was 6.4 (SD 2.3) days compared to 9 (SD 4.3) days in the control arm ( $p=0.004)$. In the first 30 days after being assigned to a group, the proportion of patients who received a repeated course of systemic antibiotics was 33\% in the PCT arm vs $38.1 \%$ in the control arm ( $p=0.757)$. Mean length of stay in the ICU was 8.4 (SD 5.3) days in the PCT arm vs 10.4 (SD 12.3) days in the control arm $(p=0.404)$. Mortality at 30 days was $22.5 \%$ in the PCT-arm vs $25 \%$ in the control arm $(p<0.0001)$. Conclusion: POC PCT guidance stimulates reduction of duration of antibiotic use in ICU, accompanied by a significant decrease in mortality. 